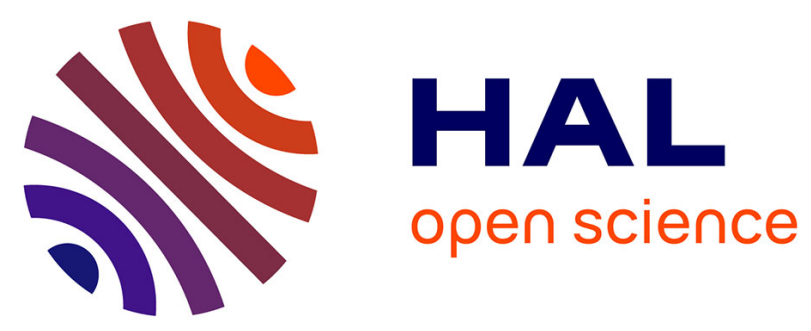

\title{
Microwave-assisted and metal-induced crystallization: a rapid and low temperature combination
}

Paul Danty, Antoine Mazel, Benoit Cormary, Maria de Marco, Joachim Allouche, Delphine Flahaut, Javier Jiménez-Lamana, Sabrina Lacomme, Marie-Hélène Delville, Glenna L. Drisko

\section{To cite this version:}

Paul Danty, Antoine Mazel, Benoit Cormary, Maria de Marco, Joachim Allouche, et al.. Microwaveassisted and metal-induced crystallization: a rapid and low temperature combination. Inorganic Chemistry, 2020, 59 (9), pp.6232-6241. 10.1021/acs.inorgchem.0c00358 . hal-02612932

\section{HAL Id: hal-02612932 \\ https://hal.science/hal-02612932}

Submitted on 20 May 2020

HAL is a multi-disciplinary open access archive for the deposit and dissemination of scientific research documents, whether they are published or not. The documents may come from teaching and research institutions in France or abroad, or from public or private research centers.
L'archive ouverte pluridisciplinaire HAL, est destinée au dépôt et à la diffusion de documents scientifiques de niveau recherche, publiés ou non, émanant des établissements d'enseignement et de recherche français ou étrangers, des laboratoires publics ou privés. 


\section{Microwave-Assisted and Metal-Induced}

\section{Crystallization: A Rapid, and Low Temperature}

\section{Combination}

Paul M. P. Danty, ${ }^{a,+}$ Antoine Mazel, ${ }^{a,+}$ Benoit Cormary,,${ }^{a,+}$ Maria L. De Marco, ${ }^{a}$ Joachim

Allouche, ${ }^{b}$ Delphine Flahaut, ${ }^{b}$ Javier Jimenez-Lamana, ${ }^{b}$ Sabrina Lacomme, ${ }^{c}$ Marie-Hélène Delville, ${ }^{a,}$ Glenna L. Drisko ${ }^{a, *}$

${ }^{a}$ CNRS, Université de Bordeaux, Bordeaux INP, ICMCB, UMR 5026, 33600 Pessac (France)

${ }^{\mathrm{b}}$ CNRS, Université de Pau \& Pays Adour, E2S UPPA, Institut des Sciences Analytiques et de Physicochimie pour l'Environnement et les Matériaux, UMR 5254, 64000 Pau (France)

${ }^{\mathrm{c}}$ Bordeaux Imaging Centre (UMS3420 CNRS - Université de Bordeaux / US4 INSERM) - 146 rue Léo Saignat, 33000 Bordeaux.

Keywords: Titania, anatase, microwave radiation, metal-induced crystallization, X-ray photoelectron spectroscopy (XPS), beads

Here we present a new crystallization process, which by combining microwaves and metal-induced devitrification, reduces both the time and the temperature of crystallization compared to other 
known methods. Titania crystallization initiates at a temperature as low as $125^{\circ} \mathrm{C}$ within a few minutes of microwave radiation. Several cations induce this low-temperature crystallization: $\mathrm{Mn}^{2+}$, $\mathrm{Co}^{2+}, \mathrm{Ni}^{2+}, \mathrm{Al}^{3+}, \mathrm{Cu}^{2+}$ and $\mathrm{Zn}^{2+}$. The crystallization mechanism is probed with electron microscopy, elemental mapping, single particle inductively plasma mass spectrometry, X-ray photoelectron spectroscopy, Auger electron spectroscopy and scanning Auger mapping. These techniques show that the metal ion migration through the vitreous titania under microwave radiation occurs prior to crystallization. The crystalline particles are suspended in solution at the end of the treatment, avoiding particle aggregation and sintering. The crystalline suspensions are thus ready for processing into a material or employment in any other application. This combination of microwaves and metal-induced crystallization is applied here to $\mathrm{TiO}_{2}$, but we are investigating its application to other materials as an ecofriendly crystallization method.

\section{Introduction}

The properties of a material depend on its crystalline state, where titanium dioxide $\left(\mathrm{TiO}_{2}\right)$ is no exception. Currently $\mathrm{TiO}_{2}$ is used in varied domains, spanning from toothpaste, to cosmetics, food, packaging, sunscreen, medication, fertilizers, paints, sensors, and photocatalysts. ${ }^{1}$ Despite its widespread use, the application of this compound has become controversial. ${ }^{2}$ France originally banned its use in food products and packaging starting from $2020,{ }^{3}$ but then revoked the decision at the beginning of 2019. However, the toxicity of $\mathrm{TiO}_{2}$ is questionable, with some studies finding a toxic effect and many others finding no toxicity. ${ }^{4}$ In fact, toxicity is a complex issue, dependent

on many physical properties, including the degree of crystallinity and phase. ${ }^{5} \mathrm{TiO}_{2}$ can be found in three main crystalline phases; anatase, rutile and brookite which differ in their physical properties (e.g. refractive index, dielectric constant, etc.) and chemical and photochemical 
reactivity. Seeing the importance and prevalence of $\mathrm{TiO}_{2}$ in modern society, ideally $\mathrm{TiO}_{2}$ would not be banned, but applied in a non-toxic form. The bottom-up synthesis of $\mathrm{TiO}_{2}$ typically generates amorphous matter, which then, through processing, is converted into the desired crystalline form or mixture of forms, while also controlling the grain size. The objective here is to reduce the time and energy required to crystallize titania, seeing the importance of crystallinity to material performance.

Crystallization can be achieved through a variety of methods. For $\mathrm{TiO}_{2}$, the most common is thermal treatment in a furnace at $400{ }^{\circ} \mathrm{C}$ or above for at least an hour. While giving good crystallinity, this method requires the sample to be in solid form and leads to particle-particle sintering. Sintering makes redispersion extremely complicated, and thus prevents further processing of nano- or micron-sized building blocks into a homogeneous, non-aggregated material. A solvothermal process can alternatively be applied to crystallize $\mathrm{TiO}_{2}$ nanoparticles without particle-particle sintering, but this requires long reaction times up to $16 \mathrm{~h}$ in caustic solutions. ${ }^{6}$ Alternatives include supercritical crystallization, gas phase crystallization, the nonhydrolytic sol-gel process ${ }^{7}$ and acid peptization. ${ }^{8-10}$ All of these approaches consume large amounts of energy, either during the thermal treatment or by using organic solvents. Reducing the crystallization time and temperature while using water and alcohol as solvents leads to an economical and environmentally friendly crystallization process. Microwave-assisted crystallization is a relatively low temperature $\left(225^{\circ} \mathrm{C}\right)$, rapid $(25 \mathrm{~min})$ and efficient method to crystallize $\mathrm{TiO}_{2} \cdot{ }^{11}$ When performed in a hydrothermal bomb, the crystallization temperature can be reduced to $140{ }^{\circ} \mathrm{C}$ under microwave treatment. ${ }^{12}$ Other examples can be referred to. ${ }^{13-17}$ Another well-known method to decrease the temperature of crystallization is metal-induced crystallization, ${ }^{18-21}$ which was first applied to titania materials by Sangani et al. in $2015 .^{22}$ This 
report showed a reduction of the crystallization temperature from 400 to $300{ }^{\circ} \mathrm{C}$ through the diffusion of gold species through a vitreous titania film. To our knowledge, no one has yet reported coupling metal-induced crystallization with microwave-assisted crystallization.

In the present work, $\mathrm{TiO}_{2}$ particles are prepared by a sol-gel process, ${ }^{6,23,24}$ yielding amorphous spheres with a diameter of about $300 \mathrm{~nm}$. These particles are then crystallized in solution by using metal-induced crystallization combined with microwave radiation. This is the first report showing that the combination of microwaves and metal-induced crystallization has a synergistic effect on the crystallization process. Depending on the applied conditions (time and temperature), the transition of amorphous titania to anatase begins at temperature as low as $125^{\circ} \mathrm{C}$ or can be as short as $5 \mathrm{~min}$. For a given reaction time, a temperature increase from 125 to $200{ }^{\circ} \mathrm{C}$ induces a crystallite growth from 3.7 to $6.3 \mathrm{~nm}$ (Figure S1a).

The mechanism of crystallization is studied using electron microscopy, single particle inductively plasma mass spectrometry, X-ray diffraction, Auger and X-ray photometry, showing that the cation seems to induce crystallization as it migrates throughout the oxide matrix. Cation association with oxygen in the matrix occurs after $10 \mathrm{~min}$ of microwave radiation, which is after the induction of crystallization. A burst of crystal nucleation occurs throughout the spheres, followed by simultaneous crystallite growth.

\section{Experimental section}

General. Titanium (IV) isoproxide (97\%), octadecyl amine (97\%), potassium chloride (99.0100.5\%), cobalt (II) chloride (97\%), nickel (II) chloride (98\%), copper (II) chloride (97\%) and zinc chloride ( $\geq 98 \%$ ) were obtained from Sigma Aldrich. Manganese (II) chloride (97\%) and ethanol were obtained from Fisher Scientific. 
Titania synthesis. All chemicals were used as received, without further purification. Amorphous titania spheres were prepared by modifying a previously published procedure. ${ }^{6}$ In a typical synthesis octadecyl amine (ODA, $2.67 \mathrm{~g}, 1 \mathrm{mmol})$ was dissolved in ethanol (800 $\mathrm{mL}$, $13.7 \mathrm{~mol})$, then a solution of $0.04 \mathrm{M} \mathrm{KCl}$ in water $(7.5 \mathrm{~mL}, 0.3 \mathrm{mmol})$ was added under moderate agitation. Titanium (IV) isopropoxide (97\%) (TiP, $18.1 \mathrm{~mL}, 64.3 \mathrm{mmol})$ was withdrawn via syringe and added rapidly as a single portion to the solution under extreme agitation. Magnetic stirring was stopped after $15 \mathrm{~min}$ of reaction time. The milky-white suspension remained static for 1 day. The molar ratio of precursors ODA: $\mathrm{H}_{2} \mathrm{O}: \mathrm{KCl}: \mathrm{EtOH}: \mathrm{TiP}$ was $1.6 \times 10^{-2}: 6.2: 4.7 \times 10^{-3}$ : 213.0:1.0. To purify the spheres, the solution was removed by passing the suspension through a frit under vacuum. The spheres were redispersed several times in fresh ethanol and each time the solution was removed by vacuum filtration until the supernatant was transparent.

Titania crystallization. For thermal treatment, an Anton Paar Microwave Reactor (Monowave 450) equipped with an Autosampler (MAS 24) was used. A portion of $100 \mathrm{mg}$ of $\mathrm{TiO}_{2}$ dispersed in $13.3 \mathrm{~mL}$ of ethanol was combined with $5 \mathrm{~mL}$ of $0.33 \mathrm{M}$ cation solution in water, and then placed in a $30 \mathrm{~mL}$ reaction vial. The solution was heated rapidly using microwaves to the target temperature, typically $150{ }^{\circ} \mathrm{C}$. The temperature was held constant for a certain time, typically $45 \mathrm{~min}$, and then the reaction vial was cooled quickly thanks to an air flux within the reactor. To recover the spheres, the suspension was placed in a centrifuge tube and centrifuged at 10,000 RPM for $10 \mathrm{~min}$. The supernatant was discarded, and the solid was dried at $70{ }^{\circ} \mathrm{C}$ overnight.

For the control experiment using convective heating, the titania was pre-infiltrated with manganese cations. The same quantity of $\mathrm{TiO}_{2}$ was dispersed in the same solution containing $\mathrm{MnCl}_{2}$ as for the microwave experiments. At this point, the suspension was stirred overnight on a hot plate at $150{ }^{\circ} \mathrm{C}$ in a hermetically sealed container $(30 \mathrm{~mL})$. The spheres were then recovered 
using the same centrifugation conditions as for the microwave-treated spheres, and dried at $70{ }^{\circ} \mathrm{C}$ overnight. The powder was placed in the XRD apparatus and diffractograms were acquired while in-situ heating by $25{ }^{\circ} \mathrm{C}$ intervals. The diffractogram at $150{ }^{\circ} \mathrm{C}$ was used as a reference sample (blue curve) in Figure 1.

Surfactant removal from $\mathrm{TiO}_{2}$. The crystalline $\mathrm{TiO}_{2}(0.6-0.8 \mathrm{~g})$ was suspended in $100 \mathrm{~mL}$ of ethanol and sonicated for $5 \mathrm{~min}$ followed by an addition of 10 drops of $1 \mathrm{M} \mathrm{HCl}$. The resulting suspension was heated to $80^{\circ} \mathrm{C}$ for $1 \mathrm{~h}$, centrifuged at $14,000 \mathrm{RPM}$ for $10 \mathrm{~min}$, and washed twice with ethanol.

Preparation of nanoparticles cross cut by ion-milling. The nanoparticle cross cut was prepared with a JEOL Cross-Polisher ${ }^{25,26}$ (JEOL Ltd., Tokyo, Japan) working under controlled atmosphere $\left(\mathrm{O}_{2}<1 \mathrm{ppm}, \mathrm{H}_{2} \mathrm{O}<1 \mathrm{ppm}\right)$. Several drops of a particle suspension in ethanol were deposited on aluminum foil before evaporating the solvent at $120^{\circ} \mathrm{C}$. The $\mathrm{Al}$ foil was then fixed on a shield plate for cutting with an $\mathrm{Ar}^{+}$beam. During this cutting process, the beam angle to the sample surface was close to $90^{\circ}$ and generated a perfect planar cut through slow material erosion. The working $\mathrm{Ar}^{+}$pressure was $1.10^{-4} \mathrm{~Pa}$ while the ion beam energy was fixed at $5 \mathrm{keV}$ for $2 \mathrm{~h}$ followed by $1 \mathrm{keV}$ for $1 \mathrm{~h}$. The ion current was approximately $80 \mu \mathrm{A}$.

Scanning electron microscopy (SEM), scanning Auger mapping (SAM) and Auger electron spectroscopy (AES). Analyses were carried out using a JEOL JAMP 9500 F Auger spectrometer (JEOL Ltd., Tokyo, Japan) working under UHV conditions (pressure $<2 \times 10^{-7} \mathrm{~Pa}$ ). The electron emitter was a Schottky field emission gun dedicated to high spatial resolution analysis and high brightness (size of the excitation electron beam $\approx 10 \mathrm{~nm}$ ). The system was fitted with a 
hemispherical analyser coupled to a high dynamic multichannel detector ( 7 channeltrons), optimal for energy-resolved analysis.

X-ray photoelectron spectroscopy (XPS). The surface atomic composition and the electronic structure of elements on the sample surface were analyzed by XPS. The survey and high resolution spectra were obtained on a Thermo Ka system with a hemispherical analyzer and a microfocused (analysis area was ca. $200 \mu \mathrm{m}^{2}$ ) monochromatized $\mathrm{Al} \mathrm{K \alpha}(1486.6 \mathrm{eV})$ radiation operating at $75 \mathrm{~W}$ under a residual pressure of $1 \times 10^{-7} \mathrm{mBar}$. The spectrometer pass energy was respectively set to $160 \mathrm{eV}$ and $20 \mathrm{eV}$ for the survey spectrum and core peak records. Sample surface charging was minimized by a neutralizer gun, which sprays low energy electrons and $\mathrm{Ar}^{+}$ions over the sample surface. The binding energy values of Ti 2p, O 1s, Mn 2p, Mn 3s and $\mathrm{Cl} 2 \mathrm{p}$ were calibrated by using the standard binding energy of adventitious carbon $(\mathrm{C} 1 \mathrm{~s}=285.0 \mathrm{eV})$ as a reference. The peak positions and areas were optimized by a weighted least-squares fitting method using $70 \%$ Gaussian and $30 \%$ Lorentzian line shapes. The quantification of surface composition was based on Scofield's relative sensitivity factors. ${ }^{27}$ CASA XPS software (CasaXPS Ltd, Teignmouth, UK) using $\mathrm{K} \alpha$ relative sensitivity factors were used to quantify and fit the spectra.

X-ray diffraction (XRD). Powder X-ray diffraction measurements were carried out with a PANalytical X'Pert Pro diffractometer equipped with a secondary monochromator $\left(\mathrm{K} \alpha_{\mathrm{Cu}}=1.5418\right.$ $\AA$ ) and an $\mathrm{X}^{\prime}$ Celerator detector over an angular range of $2 \theta=8-80^{\circ}$ with a step size of $0.0167^{\circ}$. The acquisition lasted for $34 \mathrm{~min}$. The unit cell parameters were refined by structural pattern matching using the Fullprof program package. The samples were placed on aluminum alloy sample-holders, and flattened with a flat glass substrate. For in situ high-temperature characterization, experiments were performed with a PANalytical X'Pert diffractometer with Bragg-Bentano geometry equipped with a secondary monochromator $\left(\mathrm{K} \alpha_{\mathrm{Cu}}=1.5418 \AA\right)$ and an 
Anton Paar HTK16 chamber. The chosen heating sequence recorded diffractograms of $\mathrm{TiO}_{2}$ every $25^{\circ} \mathrm{C}$ between room temperature and $800^{\circ} \mathrm{C}$, with a range from 8 to $80^{\circ}$, a step size of $0.0167^{\circ}$ and an acquisition time of $58 \mathrm{~min}$. The diffractogram at $150^{\circ} \mathrm{C}$ was used as a reference sample (blue curve) in Figure 1.

Scanning electron microscopy (SEM). The powders were fixed onto a double face carbon tape on a classical SEM stub and covered with a Au/Pt layer a few nm in thickness, deposited by plasma sputtering. A JSM 6700F GEOL microscope was used to observe the samples.

Transmission electron microscopy (TEM). $\mathrm{TiO}_{2}$ beads were embedded in LR White resin in conical gelatin capsules, and polymerized overnight at $60^{\circ} \mathrm{C}$. Samples were then sectioned using a diamond knife (Diatome, Biel-Bienne, Switzerland) on an ultramicrotome (EM UCT, Leica Microsystems, Vienna, Austria). Resin sections of $70 \mathrm{~nm}$ (nanometers) were placed on copper grids with a carbon membrane.

Grids were examined with a scanning transmission electron microscope (Talos F200S Thermofisher - Eindhoven) at $200 \mathrm{kV}$ (wavelength $\lambda=2.51 \mathrm{pm}$ ), equipped with a double EDS detector and a $4 \mathrm{~K}^{*} 4 \mathrm{~K}$ camera One View (Gatan, Paris, France). Digital diffractograms were calculated using the Gatan Digital Micrograph program. In order to be representative and statistically significant, many images from several regions of various samples were recorded and the most characteristic results are presented.

\section{Single particle inductively coupled plasma mass spectrometry (Single Particle-ICP-MS).} An Agilent 7900 ICP MS (Agilent, Tokyo, Japan) equipped with Single Nanoparticle Application Module was used. $\mathrm{TiO}_{2}$ suspensions were analyzed in TRA mode using a dwell time of $100 \mu \mathrm{s}$, and monitoring ${ }^{55} \mathrm{Mn}$ for a total analysis time of $60 \mathrm{~s}$ per sample. Transport efficiency was determined through a gold nanoparticle standard suspension with a nominal diameter of $50 \mathrm{~nm}$ 
obtained from BBI solutions (Crimlin, UK). Raw data generated by the software were treated by in-house developed programs based on Excel (Microsoft, Redmond, OR) spreadsheets to obtain mass distributions. The later were prepared in Origin 8.5 software (Northampton, MA).

Acid digestion and ICP-MS. The powders were digested in an UltraWAVE acid digestion system (Milestone, Sorisole, Italy). Concentrated $\mathrm{HNO}_{3}(4 \mathrm{~mL})$ and concentrated $\mathrm{HF}(500 \mu \mathrm{L})$ were added to approximately $10 \mathrm{mg}$ of sample. Digestion occurred by heating to $250^{\circ} \mathrm{C}$ for $25 \mathrm{~min}$ and then maintaining $250{ }^{\circ} \mathrm{C}$ for $15 \mathrm{~min}$. After digestion, the samples were diluted with ultrapure water to a final volume of $50 \mathrm{~mL}$. Further dilutions were prepared with 2 vol $\% \mathrm{HNO}_{3}$ before ICPMS analysis. Isotopes ${ }^{47} \mathrm{Ti}$ and ${ }^{55} \mathrm{Mn}$ were monitored by an Agilent $7700 \mathrm{x}$ ICP-MS.

Raman spectroscopy. A Horiba Jobin Yvon Xplora microscope equipped with a cooled Andor CCD detector was used. The excitation wavelength was $532 \mathrm{~nm}$, calibrated using a highly ordered pyrolytic graphite. The laser spot size was $\sim 1 \mu \mathrm{m}$. A grating of 1200 lines per mm was used with an Olympus objective of 50x long working distance.

\section{Results and discussion}

Synergistic effect of metal-induced and microwave-assisted crystallization. To generate the amorphous precursor spheres, titanium (IV) isopropoxide was added to a solution of octadecyl amine (ODA), ethanol and $\mathrm{KCl}$, a modification of a previously published protocol. ${ }^{6}$ The spheres were then typically heated to $150{ }^{\circ} \mathrm{C}$ under microwave radiation for $45 \mathrm{~min}$ in the presence of a metallic cation. Scanning electron microscopy (SEM) images of the spheres as synthesized and after microwave treatment in the presence of $\mathrm{MnCl}_{2}$ show the evolution of the spheres from amorphous to crystalline (Figure 1a and Figure 1b). X-ray diffraction (XRD) patterns of the as- 
synthesized spheres show no sharp peaks, confirming the amorphous nature of the particles (Figure 1c).

To elucidate the effect of combining microwaves and a devitrification agent, a series of crystallization experiments was performed with just one of these techniques. The titania particles remained amorphous when either heating in a microwave to $150{ }^{\circ} \mathrm{C}$ without a metal salt or while heating to $150{ }^{\circ} \mathrm{C}$ with the salt in a convection furnace (Figure 1c). The same treatment in the presence of a solution of $\mathrm{MnCl}_{2}$ and using microwaves afforded well-crystallized $\mathrm{TiO}_{2}{ }^{7}$ in the anatase phase. The effect is definitely due to the cation, rather than the anion (Figure S1b), while based on results from the literature,${ }^{28}$ it is also known that protons are able to induce such a process. In situ X-ray diffraction of the spheres using convection heating with and without impregnation with a $0.09 \mathrm{M} \mathrm{MnCl}_{2}$ solution showed the presence of diffraction peaks corresponding to anatase (JCPDS 21-1272) at 375 and $475{ }^{\circ} \mathrm{C}$ respectively (Figure S2). The combination of microwave radiation and the presence of a cation significantly decreases the crystallization temperature.

Metal-induced crystallization can act through several mechanisms depending on the matrix and the metal. ${ }^{29}$ In the present case, we hypothesize that the passage of the cation from one interstitial site to another stretches the Ti-O bonds (Figure 2a). When the bonds relax after the passage of the cation, they relax into the conformation with the shortest bond distances, the lower energy crystalline form. ${ }^{29}$ Perhaps the bond stretching during microwave radiation facilitates this metal migration, hence the reduction in crystallization temperature. 

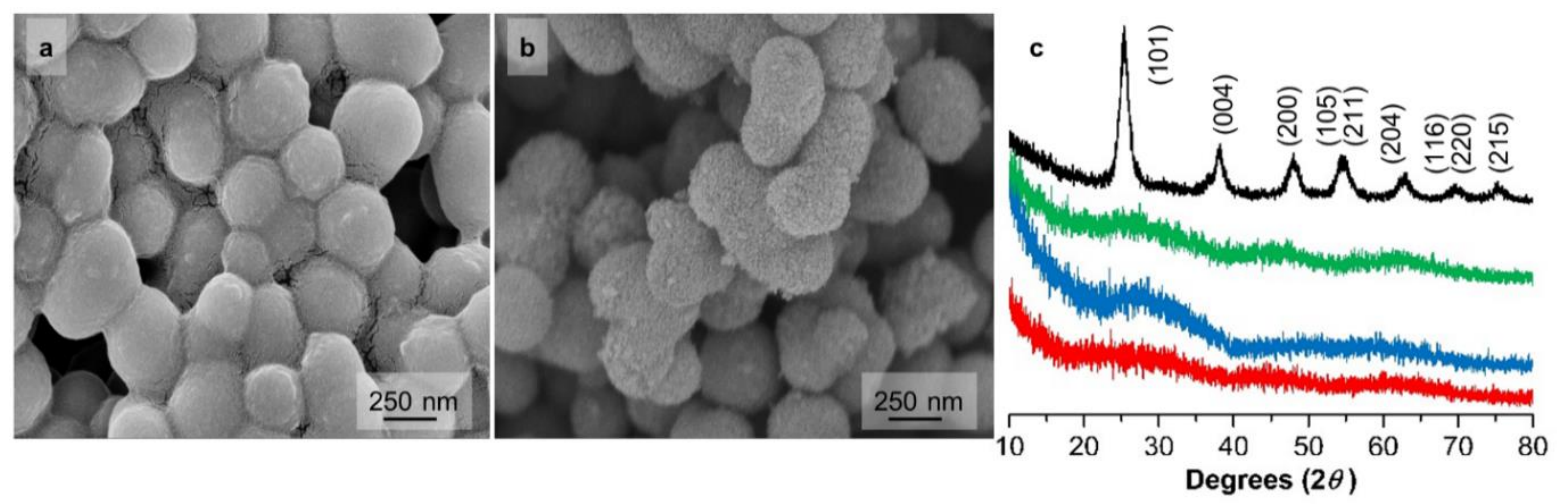

Figure 1. Synergy between microwave radiation and a devitrification agent. SEM images of spheres (a) as synthesized and (b) after microwave treatment in the presence of $\mathrm{MnCl}_{2}$. (c) X-ray diffractograms of spheres as synthesized (red), after convection heat treatment (blue), after microwave radiation (green) and after microwave treatment in the presence of $\mathrm{MnCl}_{2}$ (black). The treatment temperature was at $150{ }^{\circ} \mathrm{C}$ for $45 \mathrm{~min}$.

A generalizable technique. Several metals ions were studied to investigate whether the metalinduced crystallization was a general phenomenon. Different metallic salt solutions $\left(\mathrm{MnCl}_{2}\right.$, $\mathrm{CoCl}_{2}, \mathrm{NiCl}_{2}, \mathrm{CuCl}_{2}, \mathrm{ZnCl}_{2}$ and $\mathrm{AlCl}_{3}$ ) did induce titania crystallization under the same microwave treatment (Figure $2 b$ ). The intensity of the peaks and the crystallite size varies depending on the nature of the metal. There is a roughly linear correlation between atomic radii and crystallite size for ions with the same oxidation state and belonging to the d-block of the periodic table (Figure 2c). $\mathrm{Mn}^{2+}$ yields the biggest crystallites $(5.0 \mathrm{~nm})$, whereas $\mathrm{Al}^{3+}$ produces the smallest ones $(2.8$ $\mathrm{nm}$ ) in the series of cations studied. Manganese was chosen for the set of experiments presented here as this cation has the largest crystal grain size..$^{30}$ The different examples shown here illustrate that combining metal-induced + microwave-assisted crystallization can be achieved with a variety of different cations. 


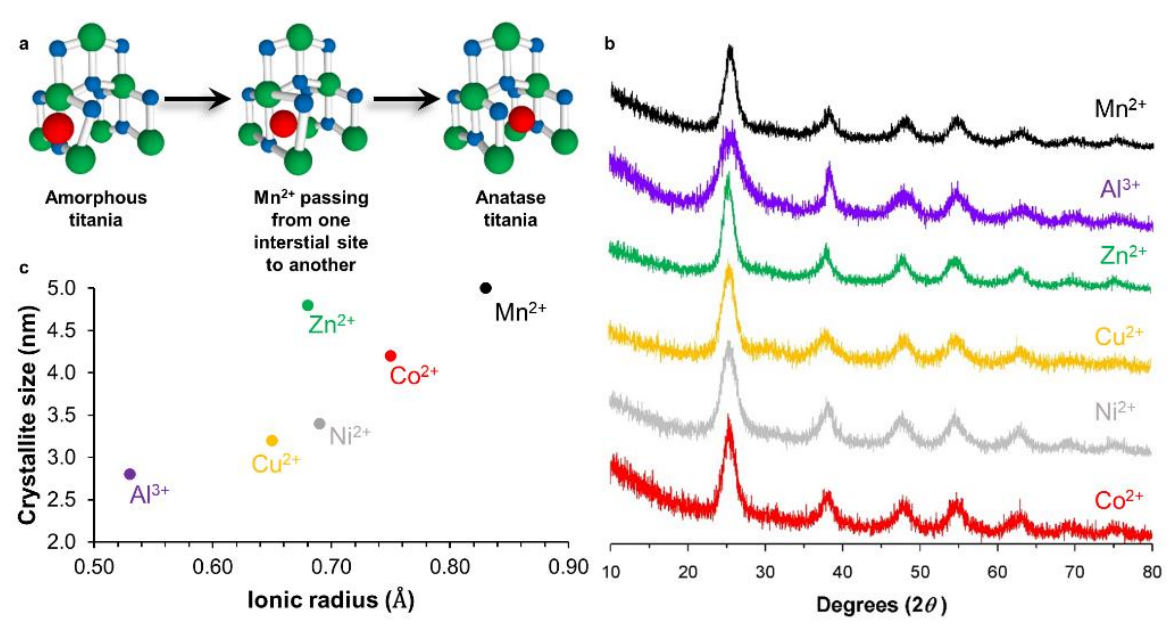

Figure 2. Diffusion of any devitrification agent induces crystallization. (a) Hypothesized metal-induced crystallization via cation diffusion through the metal oxide matrix. The spheres represent titanium atoms (green), oxygen atoms (blue) and a cation (red). (b) XRD pattern showing the impact of the nature of the cation on the crystallinity of $\mathrm{TiO}_{2}$ (JCPDS 21-1272). (c) Plot of crystallite size as a function of ionic radius. The crystallite size was calculated using the Scherrer equation. The ionic radius were obtained from reference ${ }^{31}$. The samples were treated for $45 \mathrm{~min}$ at $150{ }^{\circ} \mathrm{C}$. The concentration of cation in the solution was $0.09 \mathrm{M}$.

Metal migration in the titania matrix. The distribution of $\mathrm{Mn}^{2+}$ in the sphere and the crystallization of $\mathrm{TiO}_{2}$ were investigated by TEM EDX (Figure 3). Cross-sections of the samples immobilized in a polymer were performed before treatment and after 5, 10 and 90 min microwave radiation. EDX mapping shows a complete and homogenous distribution of $\mathrm{Mn}^{2+}$ throughout the $\mathrm{TiO}_{2}$ matrix, from the edges to the center of the particles occurring within a few minutes. Chlorine could not be detected in the inner part of the spheres using EDX mapping despite having a $\mathrm{K} \alpha$ excitation of $2.621 \mathrm{keV}$, well under the applied beam of $20 \mathrm{keV}$ indicating the migration of only the cation in the structure. No chlorine was detected either on the spheres periphery, probably because of the low quantity present in the $70 \mathrm{~nm}$ thick samples used for the EDX measurements; 
chlorine is easier to detect by XPS as illustrated later on. Dark field TEM images show the apparition of crystallites starting from 5 min of treatment, where some spheres are well crystallized and others remain amorphous.
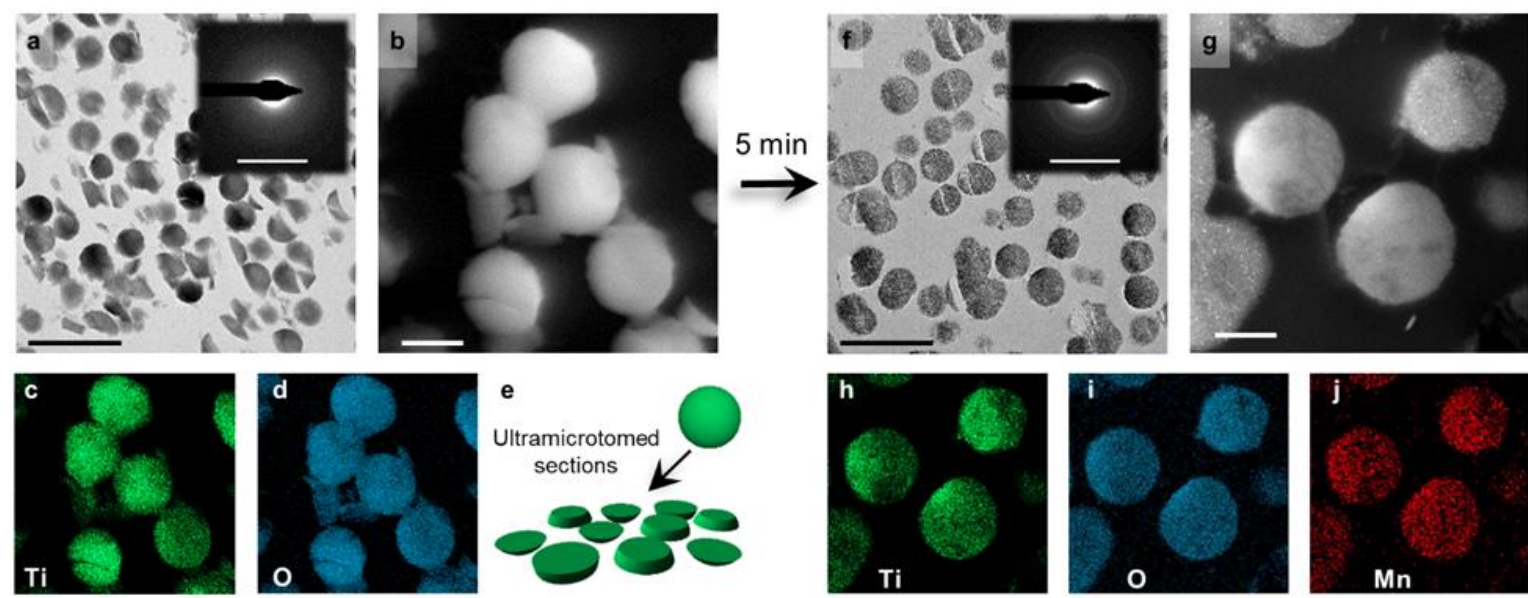

$$
\downarrow 10 \mathrm{~min}
$$
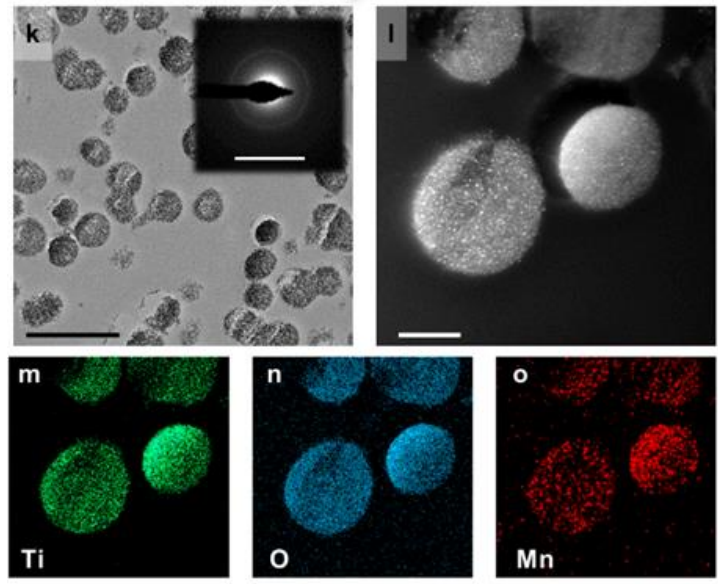

$90 \mathrm{~min}$
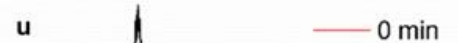

$\mathrm{Mn}$
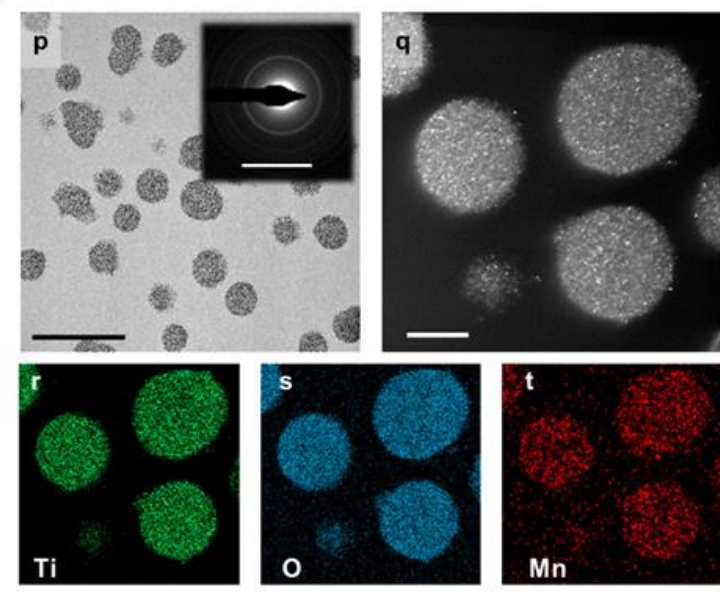

Figure 3. Relationship between $\mathrm{Mn}^{2+}$ distribution, time and crystallization. Ultramicrotomed sections $(70 \mathrm{~nm})$ of titania spheres (a-d) as synthesized and after (f-j) 5 min, (k-o) 10 min or (p-t) 90 min microwave radiation at $150{ }^{\circ} \mathrm{C}$ in the presence of $\mathrm{MnCl}_{2}$. (a,f,k,p) Bright field TEM micrographs (scale bar $=1 \mu \mathrm{m}$ ) with an inset of the selected area electron diffraction pattern (scale bar $=51 / \mathrm{nm}) .(\mathrm{b}, \mathrm{g}, 1, \mathrm{q})$ Dark field TEM micrographs (scale bar $=200 \mathrm{~nm})$. EDX analysis of $(c, h, m, r)$ Ti, $(d, i, n, s) O$ and $(j, o, t)$ Mn. (e) Pictogram of an ultramicrotomed section of spheres. 
The cation is well distributed throughout all of the particles, even those that remain amorphous after 5 or 10 min of radiation. Interestingly, very few of the spheres show a partial crystallization, they are either completely amorphous or completely crystalline. These results echo those published previously in the crystallization of $\mathrm{SiO}_{2},{ }^{18}$ where films were inexplicably either $100 \%$ crystalline or totally amorphous after heat treatment in the presence of a devitrification agent. ${ }^{32}$ This observation indicates that once crystallization is triggered, it quickly propagates throughout the titania sphere. Raman spectroscopy was used to also confirm that anatase was produced (Figure S3). ${ }^{33}$ All the spheres were fully crystalline after a 90 min treatment. To better understand the results indicated by the EDX spectra of the sectioned beads, samples after 5, 10 and 90 min of radiation were analyzed by Single Particle-ICP-MS. This technique provides a mass distribution of $\mathrm{Mn} / \mathrm{bead}$ in femtograms. The corresponding mass distributions obtained are shown in Figure 4a, where a slight increase in the amount of manganese is observed between 5 and 10 min (median masses of 0.69 and $0.92 \mathrm{fg} / \mathrm{TiO}_{2}$ sphere respectively), then the quantity remains constant between 10 and 90 min (median mass of $0.97 \mathrm{fg} / \mathrm{TiO}_{2}$ sphere). To give context, $1 \mathrm{fg}$ of $\mathrm{Mn} / \mathrm{TiO}_{2}$ sphere is equivalent to $3.34 \mathrm{~mol} \% \mathrm{Mn} / \mathrm{TiO}_{2}$. Thus, the increase in crystallinity between 10 and $90 \mathrm{~min}$ is not due to an increase in manganese absorption by the sphere, but rather due to diffusion time. As the manganese has more time to travel through the spheres, the degree of crystallinity increases (Figure 4b). The crystal grain size also increases from 3 to $5 \mathrm{~nm}$ between 5 and $10 \mathrm{~min}$ and then stays more or less constant, growing to $6 \mathrm{~nm}$ by $90 \mathrm{~min}$. The increase in relative intensity in the XRD spectrum echoes the results of electron microscopy, the sample is more crystalline with increasing crystallization time. 

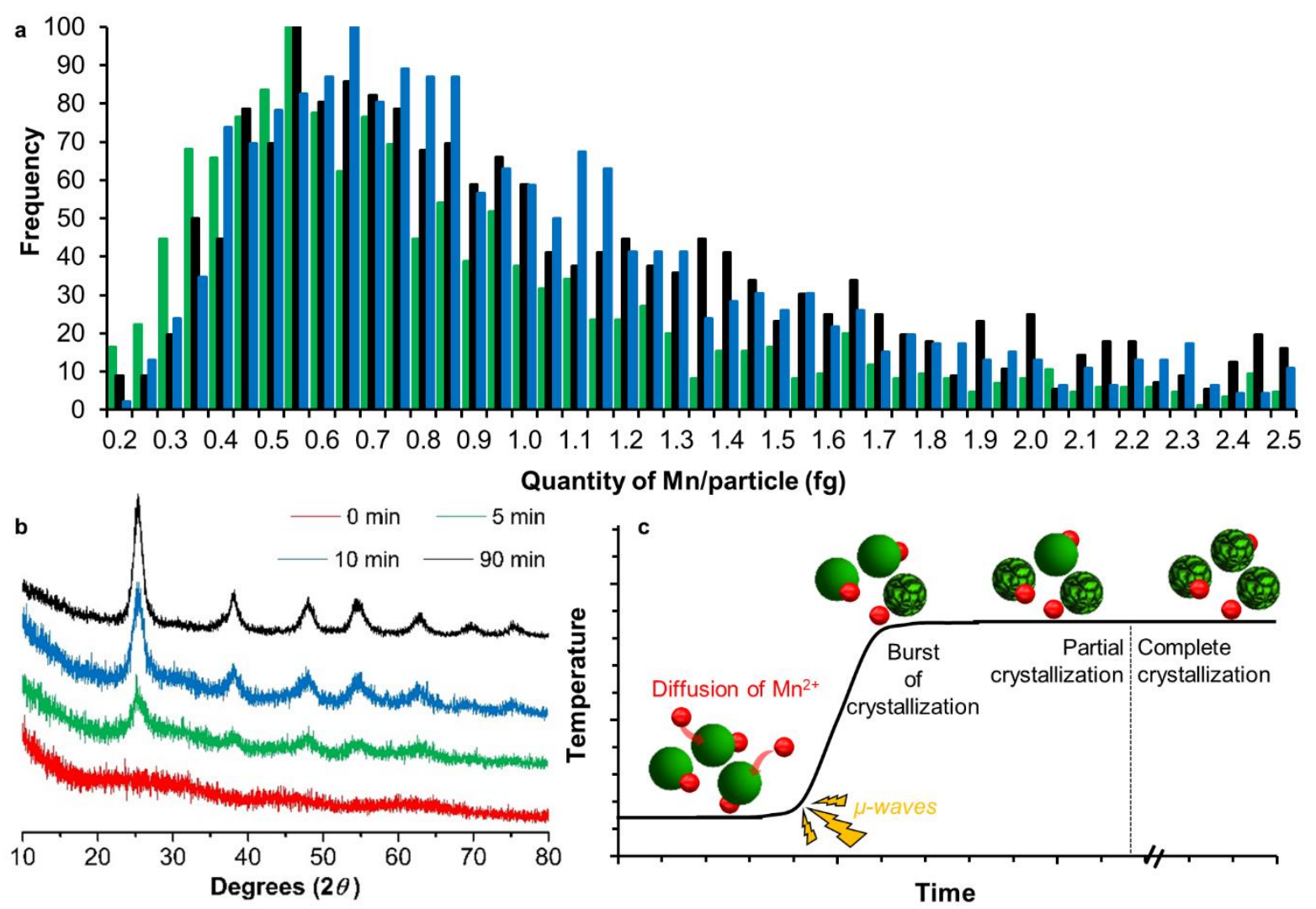

Figure 4. (a) Distribution of $\mathrm{Mn}^{2+}$ in particles in femtograms and (b) X-ray diffractograms as a function of time. Color coding is as follows: $5 \mathrm{~min}$ (green), $10 \mathrm{~min}$ (blue), $90 \mathrm{~min}$ (black). (c) Proposed mechanism of crystallization.

The total mass of Ti and Mn was determined by ICP-Ms after acid digestion of the solid samples. Using this method, a slight increase in the $\mathrm{Mn} / \mathrm{Ti}$ ratio was observed between 10 and 90 min of radiation (112 vs $135 \mu \mathrm{g} \mathrm{Mn} / \mathrm{mg}$ Ti, respectively), while no difference was observed between 5 and $10 \mathrm{~min}$. With acid digestion, this increase with increasing time indicates that the spheres are quickly saturated in $\mathrm{Mn}^{2+}$ with the microwave treatment, but with longer treatment time, a portion of the $\mathrm{Mn}^{2+}$ weakly adsorbs to the titania surface. This surface desorption is confirmed by the increase in the background signal due to unbound $\mathrm{Mn}^{2+}$ also observed between 10 and 90 min by Single Particle-ICP-MS analyses. 
We propose that the mechanism is as follows (Figure 4c): $\mathrm{Mn}^{2+}$ diffuses rapidly through the $\mathrm{TiO}_{2}$ spheres at the onset of microwave treatment. A burst of crystallization occurs as the microwaves facilitate metal diffusion due to bond stretching modes. Once crystallization begins, it propagates rapidly throughout the sphere, keeping the grain size relatively small. As time progresses more spheres become crystallized. As the spheres are quickly saturated in metal, crystallinity is dependent on the diffusion time of the devitrification agent. This burst of crystallization differs from what has been observed in $\mathrm{TiO}_{2}$ films via convective heating metal induced crystallization. In this report by Sangani, et al., ${ }^{22}$ crystallization centers appeared in a mass of amorphous titania. The difference in mechanism may be explained by the inhomogeneous distribution of $\mathrm{Au}$ in the $\mathrm{TiO}_{2}$ film. The nanometric dimensions in the current study lend themselves to a more homogeneous distribution of devitrification agents.

When $\mathrm{TiO}_{2}$ nanostructures are crystallized by calcination, the surfactant is burned away (Warning! Carcinogenic vapours are produced via calcination, thus such experiments must be performed in a well ventilated area). The surfactant is still present after microwave treatment, which may allow delicate mesostructuration to be preserved, as has been beneficial in creating mesostructured quartz. ${ }^{34}$ However, if the surfactant must be removed, it is possible to do so by refluxing in a mildly acidic solution of ethanol for $1 \mathrm{~h}$ (Figure S3). This protocol efficiently removed octadecyl amine from the titania spheres, without visibly damaging their structure or the degree of crystallinity. An infrared spectrum of the crude crystalline $\mathrm{TiO}_{2}$ showed two sharp peaks at 2920 and $2858 \mathrm{~cm}^{-1}$, which are assigned to the $\mathrm{CH}_{2}$ stretching vibrations of octadecylamine. After hot acid treatment, these bands disappeared, indicating surfactant removal.

The elemental distribution within titania spheres was studied using Auger electron spectroscopy by drop-casting samples onto an aluminum sheet and cross-cutting to study their cross-section. 
There was no significant difference in elemental distribution between samples treated in the presence of $\mathrm{MnCl}_{2}$ for 5, 10 or 90 min, attesting the rapid migration of $\mathrm{Mn}^{2+}$ in the $\mathrm{TiO}_{2}$ spheres (Figure S4). Figure 5 displays the Auger analyses of the particles after 10 min of contact with $\mathrm{MnCl}_{2}$ under microwaves. The Auger electron spectroscopy spectra of four target spots (Figure 5a) with a spot size of $10 \mathrm{~nm}$ were recorded (Figure 5b). Dots 1, 3 and 4 were located on cross-cut sections of particles whereas dot 2 targets the external surface of a particle. Figure $5 \mathrm{~b}$ shows different Auger transitions, including Cl LVV (140 to $180 \mathrm{eV}$ ), C KLL (240 to $280 \mathrm{eV}$ ), Ti LMM (340 to $460 \mathrm{eV}$ ), O KLL (460 to $520 \mathrm{eV}$ ) and Mn LMM (520 to $660 \mathrm{eV}$ ) for all dots. The chloride peak is weak, suggesting that the Mn cation diffuses through the matrix without the $\mathrm{Cl}$ counter ion. Focusing on $\mathrm{Mn}$, the element is detected in the sample material with no significant difference in the signal intensity between the dots, even when comparing dot 2 (external surface) to dots 1,3 and 4 (cross-section). There is thus a homogenous elemental distribution of Mn from the surface to the particle core. This result has been confirmed by nanoscale scanning Auger mapping images performed on single particles (Figure $5 \mathrm{c}$ to Figure 5f). From this chemical mapping, $\mathrm{Mn}$ is distributed homogeneously within the particle, in good agreement with the spectra analyses (Figure 5b) and just as observed using TEM EDX mapping (Figure 3). 


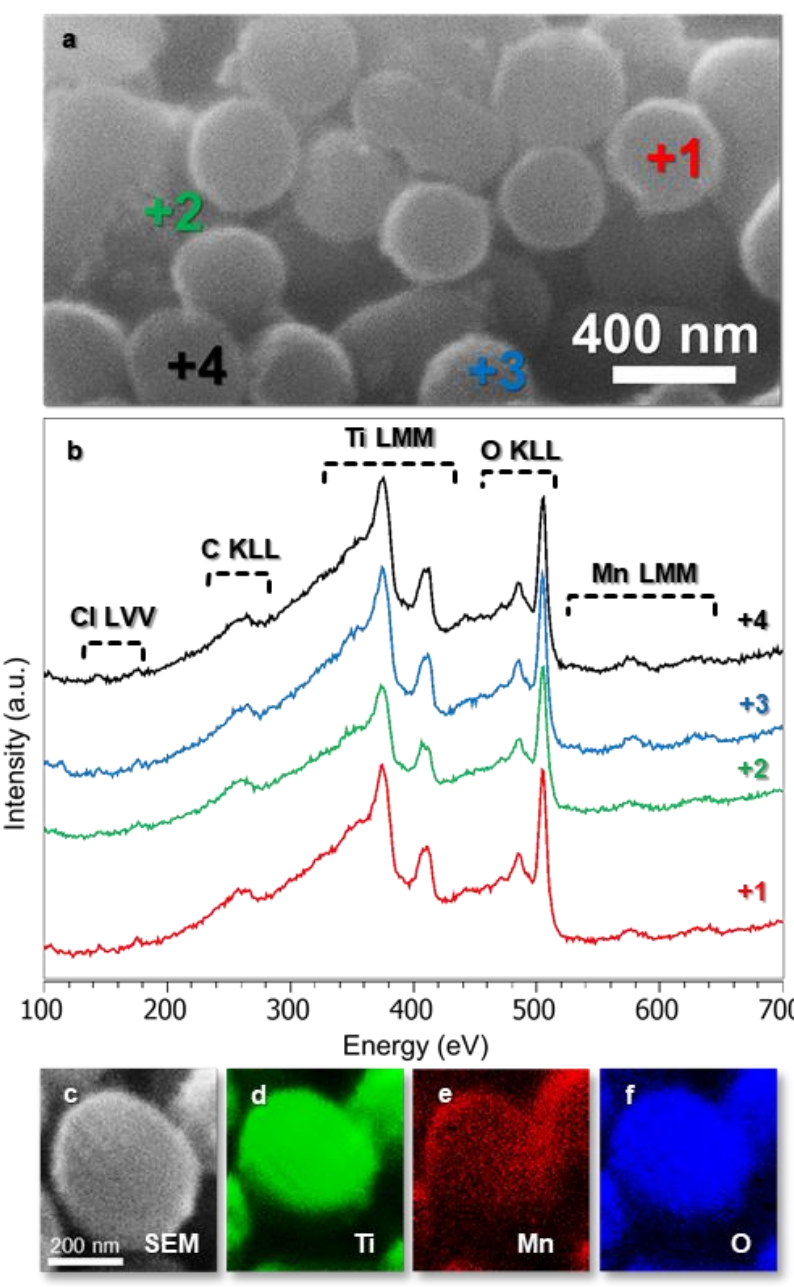

Figure 5. Auger Electron Spectroscopy analysis. SEM image of (a) the cross-cut spheres with target dots and (b) the corresponding Auger spectra of the target dots. (c) SEM image and scanning Auger mapping of (d) titanium, (e) manganese and (f) oxygen of a single particle. This sample was treated with microwave radiation in a $0.09 \mathrm{M} \mathrm{MnCl}_{2}$ solution for $10 \mathrm{~min}$.

Oxidation states support a diffusion-based mechanism. To further probe the mechanism of crystallization, XPS measurements were performed to determine the global electronic structure and composition of the spheres, with a depth profile of 5-10 nm. The Ti 2p, O 1s, Mn 3s, Mn 2p and $\mathrm{Cl} 2 \mathrm{p}$ spectra were recorded for $\mathrm{TiO}_{2}$ prior to microwave treatment, and then after 5,10 and 90 min microwave radiation times (Figure 6, Figure S5 and Figure S6). These XPS results show 
that the crystallization propagates in titania spheres from 0 to $90 \mathrm{~min}$, with the greatest amount of crystallization occurring within $5 \mathrm{~min}$. Mn existed mostly in a +II oxidation state. A small fraction of $\mathrm{Mn}$ adsorbs to the surface of the $\mathrm{TiO}_{2}$ with increasing microwave radiation time.
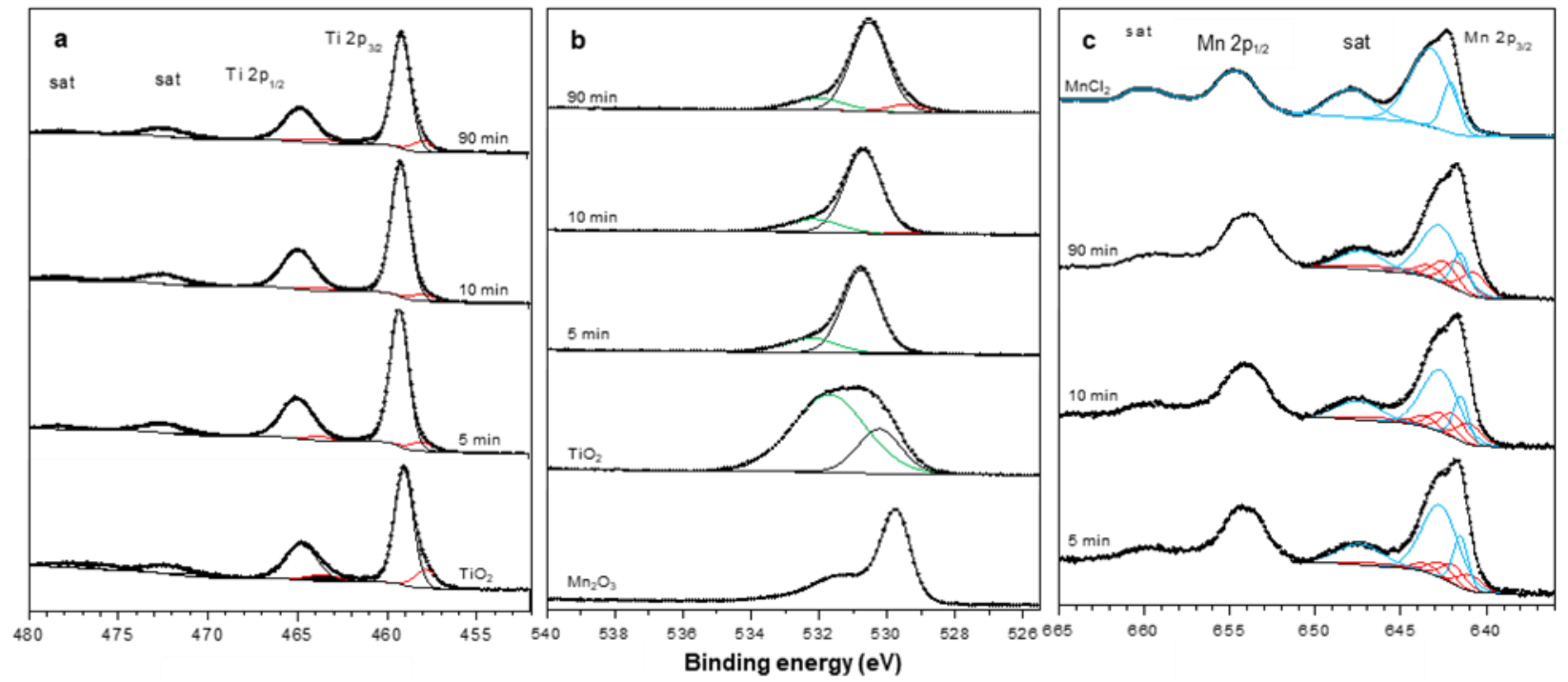

Figure 6. Determination of oxidation states. XPS core spectra of (a) Ti 2p, (b) O 1s and (c) Mn $2 \mathrm{p}$ of the titania spheres as synthesized and after $5 \mathrm{~min}, 10 \mathrm{~min}$ or $90 \mathrm{~min}$ microwave irradiation at $150{ }^{\circ} \mathrm{C}$ in the presence of $\mathrm{MnCl}_{2}$.

Ti $2 p$ core peak spectra (Figure $6 a$ ) consist of two main Ti $2 p$ components: Ti 2p $p_{3 / 2}$ (ca. 459.3 $\mathrm{eV}$ ) and Ti $2 \mathrm{p}_{1 / 2}$ (ca. $465.1 \mathrm{eV}$ ). These peaks are due to spin-orbit coupling, with charge-transfer satellite peaks at the higher binding energy side $(13 \mathrm{eV})$ associated to each main component, which are representative of the tetravalent $\mathrm{Ti}^{4+}$ cation in an oxygenated environment. ${ }^{29}$ This indicates that the electronic environment of Ti (IV) does not change from the amorphous material to 90 min of treatment. A small proportion of titanium exists in a + III oxidation state (Figure 6a, red contribution), which is either a surface defect or generated under the beam. As in the Ti $2 \mathrm{p}$ spectra, 
the $\mathrm{O} 1 \mathrm{~s}$ core peaks of all samples present the characteristics associated with the continuous crystallization of titania from 0 to $90 \mathrm{~min}$ (Figure $6 \mathrm{~b}$ ). The $\mathrm{O} 1 \mathrm{~s}$ core peaks are asymmetric, and can be decomposed into two components: a main component at $530.54 \mathrm{eV}$ attributed to the $\mathrm{O}^{2-}$ anions of the inner oxide lattice and another component at $532.2 \mathrm{eV}$ corresponding to oxygen atoms of the hydroxyl groups, adsorbed species and under coordinated oxygen present on the oxide surface. There is a strong difference in the spectra between the amorphous titania and the crystalline samples. The green contribution at $531.6 \mathrm{eV}$ of Figure $6 \mathrm{~b}$ relates to pendant hydroxyl groups, and undergoes a strong decrease of intensity as soon as the microwave radiation takes place because the crystallization process condenses the oxide network (Figure 6b, 5 min). In the same way, the XPS spectra indicate that a new oxygen environment is detected after 10 min of microwave treatment and is even more relevant at 90 min (Figure 6b, red curve). This new contribution could be assigned to the formation of Mn-O-Ti as the binding energy of $529.4 \mathrm{eV}$ corresponds to the oxide anion in a Mn network (reference spectrum bottom of Figure 6b).

The electronic structure of the manganese cations have been investigated through both Mn $3 \mathrm{~s}$ (Figure S5) and Mn 2p (Figure 6c) core peak spectra. As a multiplet splitting has been recorded in the $\mathrm{Mn} 3 \mathrm{~s}$ spectra for all the samples, the manganese is sitting in a paramagnetic state. The energy splitting between the two components of the $\mathrm{Mn} 3 \mathrm{~s}$ spectra is $6.2 \mathrm{eV}$ in $\mathrm{MnCl}_{2}$, according to the +II oxidation state. The energy splitting value is maintained whatever the treatment time, indicating the majority of Mn exists mainly in the + II oxidation state. Divalent manganese in an oxygenated environment, $\mathrm{MnO}$, has roughly the same energy splitting 5.5-6.1 eV, and could not be distinguished from $\mathrm{MnCl}_{2}$. As we do not detect a significant variation of the energy splitting in the Mn 3s spectra, we argue that the change in the satellite area of the Mn $2 p$ spectra can be assigned to a change of the $\mathrm{Mn}^{2+}$ from a chloride to an oxygenated environment. Thus, the 
decomposition of the Mn $2 p$ spectra has been performed by considering the characteristic (main peak and satellites) of the $\mathrm{Mn}^{2+}$ signature in the $\mathrm{MnCl}_{2}$ and $\mathrm{MnO}$ environments. ${ }^{35}$

The Mn $2 \mathrm{p}$ core peak of the $\mathrm{MnCl}_{2}$ reference material is described by two main components, with a binding energy of the $\mathrm{Mn} 2 \mathrm{p}_{3 / 2}$ of $642.3 \mathrm{eV}$, due to the spin orbit coupling, and two large satellites (Isat/I $2 p_{3 / 2}=0.23$ ) occurring at $5.7 \mathrm{eV}$ higher binding energy with respect to the main peak (Figure $6 \mathrm{c}$ ). A variation of the Isat / I 2 $\mathrm{p}_{3 / 2}$ ratio occurs with time, indicating a change in the manganese environment and/or oxidation state. ${ }^{36,37}$ The $\mathrm{MnO}$ reference spectrum exhibits a similar shape but with a less intense satellite. ${ }^{36}$ The $\mathrm{MnO}$ environment content increases with crystallization time from 26.7 to $39.5 \%$ for 5 to $90 \mathrm{~min}$ (red curves). This indicates that the $\mathrm{Mn}$ is covalently attaching to the $\mathrm{TiO}_{2}$ matrix. Moreover, the binding energy of the $\mathrm{Mn} 2 \mathrm{p}_{3 / 2}$ component, assigned to the $\mathrm{MnO}$ environment in our materials is slightly larger $(+0.4 \mathrm{eV})$ than those reported by Biesinger et al., indicating that the $\mathrm{Mn}^{2+}$ cations are in a more electronegative environment, such as $\mathrm{O}-\mathrm{Mn}-\mathrm{Cl} .{ }^{36}$ However, the global $\mathrm{Mn} 2 \mathrm{p}$ signature of the $\mathrm{MnCl}_{2}$ environment is shifted to a lower binding energy by $0.4 \mathrm{eV}$, in accordance with the same shift observed in the $\mathrm{Cl} 2 \mathrm{p}$ and $\mathrm{Mn}$ 3s spectrum (Figure $\mathrm{S} 6$ ). This result indicates that the presence of $\mathrm{TiO}_{2}$ does not globally impact the $\mathrm{Mn}-\mathrm{Cl}$ bond. This slight shift in binding energy is due to a change in the electronic environment after adsorbing onto the surface of titania. The totality of these spectra indicates that the majority of the manganese is migrating through the network with little electronic interaction with titania, in accordance with EDX and TEM measurements.

The hypothesized mechanism presented in Figure 2 is inconsistent with the mechanisms known to occur in silicon metal induced crystallization. In silicon, two crystallization pathways are known: a eutectic mechanism and a silicide mechanism. ${ }^{38}$ We eliminate the eutectic mixture mechanism as the melting point of $\mathrm{TiO}_{2}$ alone is $1843^{\circ} \mathrm{C}$. Its mixtures with other oxides does not 
lower the melting temperature by $1700{ }^{\circ} \mathrm{C}$. Moreover, melting would lead to a loss of spherical shape, which is not the case. We also eliminate the silicide-equivalent mechanism as XPS studies showed that Mn-O-Ti bonds form after, not prior to, the onset of crystallization. To fully understand the mechanism, X-ray absorption fine structure studies should be performed, as has been done for silicon. ${ }^{39}$ Thus we have presented the metal-induced crystallization mechanism proposed for silica, ${ }^{18-20}$ which depends on cationic diffusivity work by Anderson and Stuart. ${ }^{40}$

\section{Conclusions}

In order to move away from a carbon-intensive economy, new synthetic methods that not only replace organic solvents by water, but also require less energy, need to be developed. This metalinduced + microwave-assisted crystallization method responds to these requirements, reducing the temperature of treatment, reducing the treatment time and using a mixture of water and ethanol for the process. The technique works with a series of d-block elements and a p-block element, and could likely be extended to s-block and other p-block metals. Under microwave radiation, the metal ion rapidly diffuses homogeneously throughout the titania spheres, initiating crystallization within a few minutes. The treatment time influences the degree of crystallinity; the treatment temperature and the metal used determine the crystallite size. This is a key point, since the $\mathrm{TiO}_{2}$ properties, such as photocatalytic activity, are known to be dependent on crystallite size, thus it is advantageous that this crystallization method provides fine control over this parameter. Moreover, the presence of metal species in the titania structure ${ }^{415}$ may prove to be beneficial to photocatalytic properties. Experiments to determine photocatalytic activity of metal-induced crystallization titania samples are currently in process. Further efforts will focus on adapting this technique to access other crystalline forms, e.g. rutile titania, quartz silica and barium titanate. Additionally the 
effect of the metal devitrification agents within the titania structure on its properties, such as photocatalytic activity, will soon be addressed.

\section{ASSOCIATED CONTENT}

Supporting Information. The following files are available free of charge.

XRD of samples treated at varying temperature, in situ XRD convection heating, scanning Auger mapping and XPS spectra of Mn 3s and $\mathrm{Cl} 2 \mathrm{p}$.

\section{AUTHOR INFORMATION}

\section{Corresponding Author}

* CNRS, Université de Bordeaux, Bordeaux INP, ICMCB, UMR 5026, 33600 Pessac (France) E-mail: marie-helene.delville@icmcb.cnrs.fr; glenna.drisko@icmcb.cnrs.fr

\section{Present Addresses}

$\dagger$ Present address: Mathym, 22 rue des Aulnes, 69410 Champagne-au-Mont-d'Or E maii: benoit.cormary@mathym.com.

\section{Author Contributions}

PMPD synthesized all materials. AM and GLD wrote the manuscript. BC, GLD and MHD conceived the project and designed experiments. MLDM performed characterization. JA performed Auger characterization and interpretation. DF performed XPS characterization and 
interpretation. GLD financed the research. All authors have given approval to the final version of the manuscript. $₫$ These authors contributed equally.

\section{Funding Sources}

LabEx AMADEus and the French Agence Nationale de la Recherche.

\section{ACKNOWLEDGMENT}

AM, MLDM, BC and GLD are supported by the LabEx AMADEus (ANR-10-LABX-42) in the framework of IdEx Bordeaux (ANR-10-IDEX-03-02), i.e. the Investissements d'Avenir program of the French government managed by the Agence Nationale de la Recherche. JA and DF acknowledge CNRS and the French Aquitaine region. Sabrina Lacomme acquired the TEM images and mapping at the Bordeaux Imaging Center, member of the FranceBioImaging national infrastructure (ANR-10-INBS-04). Eric Labraud performed XRD experiments through the XRD service of the ICMCB.

\section{REFERENCES}

1. Cargnello, M.; Gordon, T. R.; Murray, C. B., Solution-Phase Synthesis of Titanium Dioxide Nanoparticles and Nanocrystals. Chemical Reviews 2014, 114, 9319-9345.

2. Baranowska-Wójcik, E.; Szwajgier, D.; Oleszczuk, P.; Winiarska-Mieczan, A., Effects of Titanium Dioxide Nanoparticles Exposure on Human Health-a Review. Biological Trace Element Research 2020, 193, 118-129.

3. Coppens, P.; Planchenstainer, F., The Labelling of Nanomaterials under EU Law, with a Particular Focus on France. European Food and Feed Law Review 2019, 14. 
4. $\quad$ Barthes, J.; Ciftci, S.; Ponzio, F.; Knopf-Marques, H.; Pelyhe, L.; Gudima, A.; Kientzl, I.; Bognár, E.; Weszl, M.; Kzhyshkowska, J.; Vrana, N. E., Review: the potential impact of surface crystalline states of titanium for biomedical applications. Critical Reviews in Biotechnology 2018, $38,423-437$.

5. Li, K.; Qian, J.; Wang, P.; Wang, C.; Fan, X.; Lu, B.; Tian, X.; Jin, W.; He, X.; Guo, W., Toxicity of Three Crystalline $\mathrm{TiO}_{2}$ Nanoparticles in Activated Sludge: Bacterial Cell Death Modes Differentially Weaken Sludge Dewaterability. Environmental Science \& Technology 2019, 53, $4542-4555$.

6. Chen, D.; Huang, F.; Cheng, Y.-B.; Caruso, R. A., Mesoporous Anatase $\mathrm{TiO}_{2}$ Beads with High Surface Areas and Controllable Pore Sizes: A Superior Candidate for High-Performance Dye-Sensitized Solar Cells. Advanced Materials 2009, 21, 2206-2210.

7. Niederberger, M.; Bartl, M. H.; Stucky, G. D., Benzyl Alcohol and Titanium Tetrachloride A Versatile Reaction System for the Nonaqueous and Low-Temperature Preparation of Crystalline and Luminescent Titania Nanoparticles. Chemistry of Materials 2002, 14, 4364-4370.

8. Adschiri, T.; Kanazawa, K.; Arai, K., Rapid and Continuous Hydrothermal Crystallization of Metal Oxide Particles in Supercritical Water. Journal of the American Ceramic Society 1992, $75,1019-1022$.

9. Ahonen, P. P.; Moisala, A.; Tapper, U.; Brown, D. P.; Jokiniemi, J. K.; Kauppinen, E. I., Gas-phase Crystallization of Titanium Dioxide Nanoparticles. Journal of Nanoparticle Research 2002, 4, 43-52.

10. Hyunho, S.; Suk, J. H.; Sun, H. K.; Jung-Kun, L., Crystallization Process of $\mathrm{TiO}_{2}$ Nanoparticles in an Acidic Solution. Chemistry Letters 2004, 33, 1382-1383. 
11. Hart, J. N.; Cervini, R.; Cheng, Y. B.; Simon, G. P.; Spiccia, L., Formation of Anatase $\mathrm{TiO}_{2}$ by Microwave Processing. Solar Energy Materials and Solar Cells 2004, 84, 135-143.

12. Wu, W.-Y.; Tsou, Y.-Y., $\mathrm{TiO}_{2}$ Beads as Photocatalyst and Photoelectrode for DyeSensitized Solar Cells Synthesized by a Microwave-Assisted Hydrothermal Method. Int. J. Energy Res. 2015, 39, 1420-1429.

13. Aquino, J. M.; Rocha-Filho, R. C.; Bocchi, N.; Biaggio, S. R., Microwave-assisted crystallization into anatase of amorphous $\mathrm{TiO}_{2}$ nanotubes electrochemically grown on a $\mathrm{Ti}$ substrate. Mater. Lett. 2014, 126, 52-54.

14. Chen, P.; Peng, J.-D.; Liao, C.-H.; Shen, P.-S.; Kuo, P.-L., Microwave-Assisted Hydrothermal Synthesis Of TiO2 Spheres With Efficient Photovoltaic Performance For DyeSensitized Solar Cells. J. Nanopart. Res. 2013, 15, 1465/1461-1465/1411, 1411 pp.

15. de Mendonca, V. R.; Lopes, O. F.; Avansi, W., Jr.; Arenal, R.; Ribeiro, C., Insights Into Formation Of Anatase TiO2 Nanoparticles From Peroxo Titanium Complex Degradation Under Microwave-Assisted Hydrothermal Treatment. Ceram. Int. 2019, 45, 22998-23006.

16. Suzuki, A.; Yamaguchi, H.; Kageyama, H.; Oaki, Y.; Imai, H., Microwave-Assisted Rapid Synthesis of Anatase $\mathrm{TiO}^{2}$ Nanosized Particles in an Ionic Liquid-Water System. J. Ceram. Soc. Jpn. 2015, 123, 79-82/71-79-82/74, 74 pp.

17. Yang, Y.; Wang, G.; Deng, Q.; Ng, D. H. L.; Zhao, H., Microwave-Assisted Fabrication of Nanoparticulate $\mathrm{TiO}_{2}$ Microspheres for Synergistic Photocatalytic Removal of $\mathrm{Cr}(\mathrm{VI})$ and Methyl Orange. ACS Appl. Mater. Interfaces 2014, 6, 3008-3015.

18. Carretero-Genevrier, A.; Gich, M.; Picas, L.; Gazquez, J.; Drisko, G. L.; Boissiere, C.; Grosso, D.; Rodriguez-Carvajal, J.; Sanchez, C., Soft-Chemistry-Based Routes to Epitaxial $\alpha$ Quartz Thin Films with Tunable Textures. Science 2013, 340, 827. 
19. Drisko, G. L.; Carretero-Genevrier, A.; Gich, M.; Gàzquez, J.; Ferrah, D.; Grosso, D.; Boissière, C.; Rodriguez-Carvajal, J.; Sanchez, C., Water-Induced Phase Separation Forming Macrostructured Epitaxial Quartz Films on Silicon. Advanced Functional Materials 2014, 24, 5494-5502.

20. Drisko, G. L.; Carretero-Genevrier, A.; Perrot, A.; Gich, M.; Gàzquez, J.; RodriguezCarvajal, J.; Favre, L.; Grosso, D.; Boissière, C.; Sanchez, C., Crystallization of Hollow Mesoporous Silica Nanoparticles. Chemical Communications 2015, 51, 4164-4167.

21. Hou, C.-H.; Shyue, J.-J.; Su, W.-F.; Tsai, F.-Y., Catalytic Metal-Induced Crystallization of Sol-Gel Metal Oxides for High-Efficiency Flexible Perovskite. Journal of Materials Chemistry A 2018, $6,16450-16457$.

22. Sangani, L. D. V.; Sri, K. V.; Mohiddon, M. A.; Krishna, M. G., Low Temperature Au Induced Crystallization of Titanium Dioxide Thin Films for Resistive Switching Applications. RSC Advances 2015, 5, 67493-67499.

23. Chen, D.; Cao, L.; Huang, F.; Imperia, P.; Cheng, Y.-B.; Caruso, R. A., Synthesis of Monodisperse Mesoporous Titania Beads with Controllable Diameter, High Surface Areas, and Variable Pore Diameters (14-23 nm). Journal of the American Chemical Society 2010, 132, 44384444.

24. Cao, L.; Chen, D.; Wu, W.-Q.; Tan, J. Z. Y.; Caruso, R. A., Monodisperse anatase titania microspheres with high-thermal stability and large pore size $(80 \mathrm{~nm})$ as efficient photocatalysts. Journal of Materials Chemistry A 2017, 5, 3645-3654.

25. Tsutsumi, K., Auger Analysis of Cross Sections Prepared by Cross Section Polisher. JEOL News 2006, 41, 46-53. 
26. Ledeuil, J. B.; Uhart, A.; Soulé, S.; Allouche, J.; Dupin, J. C.; Martinez, H., New insights into Micro/Nanoscale Combined Probes (NanoAuger, $\mu \mathrm{XPS}$ ) to Characterize Ag/Au@ $\mathrm{SiO}_{2}$ CoreShell Assemblies. Nanoscale 2014, 6, 11130-11140.

27. Scofield, J. H., Hartree-Slater Subshell Photoionization Cross-Sections at 1254 and 1487 eV. Journal of Electron Spectroscopy and Related Phenomena 1976, 8, 129-137.

28. Garcia, A. P.; Guaglianoni, W. C.; Garcia, D. R.; Soares, L. G.; de Oliveira Vaz, M.; Teixeira, S. R.; Pereira, M. B.; Basegio, T. M.; Clemens, F. J.; Alves, A. K.; Rodembusch, F. S.; Bergmann, C. P., Facile Synthesis by Peroxide Method and Microwave-Assisted Hydrothermal Treatment of $\mathrm{TiO}_{2}$ with High Photocatalytic Efficiency for Dye Degradation and Hydrogen Production. ChemistrySelect 2018, 3, 11454-11459.

29. Wang, Z.; Jeurgens, L. P. H.; Mittemeijer, E. J.; Editors, Metal-Induced Crystallization: Fundamentals and Applications. Pan Stanford Publishing Pte. Ltd.: 2015; p 308 pp.

30. Cormary, B.; Drisko, G. L.; De Marco, M. L. Procédé de dDécontamination par MicroOndes Utilisant un Absorbeur d'Oxyde Métallique, French patent, FR19 04282, 23 April 2019, .

31. Shannon, R. D., Revised Effective Ionic Radii and Systematic Studies of Interatomic Distances in Halides and Chalcogenides. Acta Crystallographica Section A 1976, 32, 751-767.

32. Brinker, C. J.; Clem, P. G., Quartz on Silicon. Science 2013, 340, 818-819.

33. Choi, H. C.; Jung, Y. M.; Kim, S. B., Size Effects in the Raman Spectra of $\mathrm{TiO}_{2}$ Nanoparticles. Vibrational Spectroscopy 2005, 37, 33-38.

34. Matsuno, T.; Kuroda, Y.; Kitahara, M.; Shimojima, A.; Wada, H.; Kuroda, K., A SingleCrystalline Mesoporous Quartz Superlattice. Angewandte Chemie International Edition 2016, 55, 6008-6012. 
35. Khoa Le, T.; Flahaut, D.; Martinez, H.; Hung Nguyen, H. K.; Xuan Huynh, T. K., Study of the Effects of Surface Modification by Thermal Shock Method on Photocatalytic Activity of $\mathrm{TiO}_{2} \mathrm{P} 25$. Applied Catalysis B: Environmental 2015, 165, 260-268.

36. Biesinger, M. C.; Payne, B. P.; Grosvenor, A. P.; Lau, L. W. M.; Gerson, A. R.; Smart, R. S. C., Resolving surface chemical states in XPS analysis of first row transition metals, oxides and hydroxides: Cr, Mn, Fe, Co and Ni. Applied Surface Science 2011, 257, 2717-2730.

37. Quesne-Turin, A.; Vallverdu, G.; Flahaut, D.; Allouche, J.; Croguennec, L.; Ménétrier, M.; Baraille, I., Morphology and Surface Reactivity Relationship in the $\mathrm{Li}_{1+\mathrm{x}} \mathrm{Mn}_{2-\mathrm{x}} \mathrm{O}_{4}$ Spinel with $\mathrm{x}=$ 0.05 and 0.10: A Combined First-Principle and Experimental Study. ACS Applied Materials \& Interfaces 2017, 9, 44922-44930.

38. Knaepen, W.; Detavernier, C.; Van Meirhaeghe, R. L.; Jordan Sweet, J.; Lavoie, C., Insitu X-ray Diffraction study of Metal Induced Crystallization of Amorphous Silicon. Thin Solid Films 2008, 516, 4946-4952.

39. Mohiddon, M. A.; Naidu, K. L.; Krishna, M. G.; Dalba, G.; Ahmed, S. I.; Rocca, F., Chromium Oxide as a Metal Diffusion Barrier Layer: An X-Ray Absorption Fine Structure Spectroscopy Study. Journal of Applied Physics 2014, 115, 044315.

40. Anderson, O. L.; Stuart, D. A., Calculation of Activation Energy of Ionic Conductivity in Silica Glasses by Classical Methods. Journal of the American Ceramic Society 1954, 37, 573-580.

41. Binas, V. D.; Sambani, K.; Maggos, T.; Katsanaki, A.; Kiriakidis, G., Synthesis and photocatalytic activity of Mn-doped $\mathrm{TiO}_{2}$ nanostructured powders under UV and visible light. Applied Catalysis B: Environmental 2012, 113-114, 79-86. 


\section{TOC graphic}

By combining two crystallization techniques, titania is crystallized in aqueous solution within a few minutes, thus achieving a more performant material while minimizing pollution and saving energy and time.

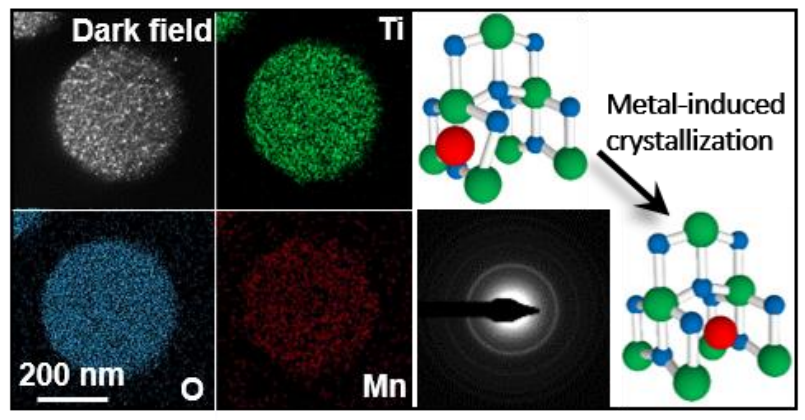

